\title{
Ciência e produção do conhecimento contemporâneo na perspectiva da criatividade
} Science and production of contemporary knowledge in view of creativity http://dx.doi.org/10.5007/2178-4582.2015v49n1p2

\author{
Maria José de Pinho \\ Kênia Paulino de Queiroz Souza \\ Universidade Federal do Tocantins, Palmas/TO, Brasil
}

\begin{abstract}
Este artigo tem como objetivo analisar a visão de ciência e produção de conhecimento na modernidade e sua transição para a contemporaneidade na acepção de uma educação pautada na criatividade que valoriza os diversos saberes. Esta reflexão é de caráter bibliográfico com a abordagem qualitativa. Sua fundamentação teórica traz a percepção dos conceitos de paradigma tradicional no contexto da ciência moderna e o paradigma emergente na atualidade com uma visão transdisciplinar e criativa contemplando o todo da vida, a partir do fazer pedagógico enquanto produção do conhecimento. É perceptível que a perspectiva contemporânea da criatividade, numa visão transformadora, tem buscado a religação dos saberes que envolvem todos os espaços da humanidade, valorizando a imaginação, a originalidade, a flexibilidade, o pensar, o sentir e o aprender dentro dos aspectos que englobam a completude da vida no planeta.
\end{abstract}

Palavras-chave: Mudança paradigmática - Criatividade - Transdisciplinaridade - Prática pedagógica.
This article aims to analyze the vision of science and knowledge production in modernity and its transition to the contemporary in the sense of a guided education in creativity that values the several types of knowledge. This is a reflection of bibliographical character with a qualitative approach. Its theoretical foundation brings the perception of concepts of the traditional paradigm within the context of modern science and the current emerging paradigm based on an interdisciplinary and creative vision that contemplates life as whole and the pedagogical practice as production of knowledge. It is noticeable that the contemporary perspective of creativity, in a transforming vision, has sought the reconnection of knowledge involving all areas of humanity, valuing imagination, originality, flexibility, thinking, feeling and learning within the aspects that encompass the fullness of life on the planet.

Keywords: Paradigmatic change - Creativity Transdisciplinary - Educational Practice.

\section{Introdução}

A perspectiva do contexto educacional atual, na visão de um ensino criativo, passa pelo caminho de transições paradigmáticas há algumas décadas, pois a criatividade na visão transdisciplinar e ecoformadora no fazer pedagógico se fundamenta em um paradigma que considera como essencial ir além do que é reconhecido pela ciência e valoriza os diferentes saberes que fazem parte da produção do conhecimento e da vida. 
A proposta da concepção ecoformadora no âmbito educacional reconhece tudo que é vida como um todo que integra o desenvolvimento do ser humano. Nesse sentido, desde o início deste século "[...] houve a preocupação em repensar os paradigmas educacionais vigentes, redefinindo objetivos, para que novos modos de vida, envolvendo os planos individuais, sociais, ecológicos e planetários se transformassem em realidade" (MORAES, 2008, p. 266). Essa concepção, que trouxe para o atual cenário do campo educacional a proposta de formação e transformação do todo que envolve a vida, faz-se imprescindível neste contexto. Pois, diante de tantos conflitos sociais, políticos, culturais e pedagógicos, este período é percebido como uma época de macro-transições das mais importantes da história, considerando-se que esta mudança de paradigma é imprescindível para a sobrevivência de todos os seres, da vida (LASZLO, 2001 apud MORAES, 2008).

A contemporaneidade educativa, com perspectivas de mudanças que envolvem o social, individual, ecológico e planetário, vê a necessidade de ampliar as valorizações para além da ciência, agregando novas formas de produção de conhecimento para a construção de uma educação integral e diferenciada.

Nesta perspectiva de transições, o presente artigo pretende analisar a visão de ciência e produção do conhecimento na modernidade e sua transição para a contemporaneidade na acepção de uma educação pautada na criatividade que valoriza os diversos saberes. Para alcançar o objetivo proposto, este trabalho se caracteriza como uma pesquisa bibliográfica de abordagem qualitativa que se fundamenta nos principais teóricos da área: Maura (2009), Moraes (1997 e 2008), Santos (2006) e Kuhn (1970).

Nesse sentido, faz-se necessário percorrer o caminho da mudança paradigmática entre o período da modernidade - época essa em que apenas a ciência era considerada como importante na produção do conhecimento - e o contexto da atualidade com o paradigma emergente que, além da ciência, valoriza diferentes saberes, numa perspectiva transdisciplinar e transformadora no contexto da prática pedagógica com indícios de criatividade. Percebe-se, assim, que o âmbito educacional contemporâneo apresenta um cenário diferente de tudo que foi vivenciado na modernidade.

Para tanto, compreende-se como essencial nos tempos atuais, o desenvolvimento da criatividade na perspectiva que valoriza o ser humano, a vida de dentro para fora e, sobretudo, que motiva o crescimento a partir do diálogo com os saberes diversos, buscando transcender os muros dos centros educativos para, então, formar seres protagonistas e transformadores de adversidades com oportunidades de crescimento. 


\section{A transição do paradigma da ciência moderna para o paradigma emergente}

O início do período da modernidade foi marcado pela supervalorização exclusiva da ciência. Os saberes advindos do senso comum não eram considerados, pois a comunidade científica, soberana nesta decisão, não os legitimava por considerá-los saberes que não eram frutos de uma produção cientificamente comprovada e sim apenas empírica.

Esta acepção do contexto moderno é reafirmada por Santos (2006, p. 24) ao explicitar que "esta nova visão do mundo e da vida reconduz-se a duas distinções fundamentais, entre conhecimento científico e conhecimento do senso comum, por um lado, e entre natureza e pessoa humana, por outro". Embora, sejam saberes que deveriam agregar-se ao contexto contemporâneo da vida do ser humano, na modernidade vivia-se tudo só pela ciência e a total negação do senso comum fortalecendo as produções do conhecimento. Tanto que "ao contrário da ciência aristotélica, a ciência moderna desconfia sistematicamente das evidências da nossa experiência imediata. Tais evidências, que estão na base do conhecimento vulgar, são ilusórias" (SANTOS, 2006, p. 24).

Diante desta superioridade científica, faz-se imprescindível conhecer a ciência e a produção do conhecimento na modernidade a partir da evolução das ciências. Thomas Kuhn traz estas questões de forma descritiva mas, sobretudo bem reflexivas. Para este autor, o conceito de ciência, nesta época, necessitava ser mudado, ampliado, pois, considera que:

\footnotetext{
[...] a ciência é a reunião de fatos, teorias e métodos reunidos nos textos atuais, então os cientistas são homens que, com ou sem sucesso, empenharam-se em contribuir com um ou outro elemento para essa constelação específica. [...] Preocupado com o desenvolvimento científico, o historiador parece então ter duas tarefas principais. De um lado deve determinar quando e por quem cada fato, teoria ou lei científica contemporânea foi descoberta ou inventada. De outro lado, deve descrever e explicar os amontoados de erros, mitos e superstições que inibiram a acumulação mais rápida dos elementos constituintes do moderno texto científico. Muita pesquisa foi dirigida para esses fins e alguma ainda é. (KUHN, 1970, p. 20)
}

Esta concepção de ciência é criticada pelo autor como mera descrição de dados, métodos, mas logo ele explicita que precisa-se ir além disso e propiciar muito mais que fatos e teorias científicas descritivas.

A ciência moderna fundamentava-se nas diretrizes de um paradigma hegemônico, para cada contexto, algo que só se diferencia de hoje pelo fato de se 
ter mais paradigmas, mas também sempre há um dominante para cada âmbito. Kuhn (1970, p. 13) afirma inicialmente que paradigmas são "as realizações científicas universalmente reconhecidas que, durante algum tempo, fornecem problemas e soluções modelares para uma comunidade de praticantes de uma ciência"; e ainda explicita, no final, a acepção de que "um paradigma é aquilo que os membros de uma comunidade partilham e, inversamente, uma comunidade científica consiste em homens que partilham um paradigma" (KUHN, 1970, p. 219).

Percebe-se que, de acordo com as condições e caminhos escolhidos para resolver os conflitos de origem externa, no contexto social, além dos métodos selecionados para solucionar as crises internas, no âmbito educacional prevalece, ainda atualmente, nas diferentes dimensões da vida humana, o paradigma moderno. A escolha de uma teoria ou de um modelo para resolver situações adversas só muda para novas concepções a partir do momento em que surgem situações problema que o modelo hegemônico não consegue mais resolver; o paradigma entra em crise e pode até surgir uma revolução científica. Segundo Kuhn (1970), esta revolução torna-se real a partir de uma mudança drástica de padrão a ser seguido, a total incredibilidade no anterior e em tudo que o compunha chegando ao ponto de ser completamente descartado. Assim, diante da necessidade de encontrar alternativas, surgem novos modelos para atender a realidade de tal sociedade.

A produção do conhecimento no período moderno surge em duas circunstâncias: uma, em momentos de ausência de crises, conflitos, em forma acumulativa, momento caracterizado por Kuhn (1970) de ciência normal, que acumulava os conhecimentos; em outra, já em crises e revoluções, a construção se dava partir de novos estudos, não se acumulava com nada do paradigma anterior, ao contrário, havia o descarte total das teorias e de tudo que se referisse ao modelo antigo, pois "um paradigma governa, em primeiro lugar, não um objeto de estudo, mas um grupo de praticantes da ciência" (KUHN, 1970, p. 224). Uma comunidade científica recomeçava com novos conhecimentos para solucionar as situações problema que se apresentavam na sociedade ou em seu contexto interno por esgotamento teórico. Como exemplo de uma revolução, Kuhn apresenta a mudança da teoria do geocentrismo para o heliocentrismo que marcou a história da ciência como um abalo em todas as suas estruturas teóricas.

Um dos períodos mais marcantes e significativos de crise de paradigmas é exatamente a revolução científica dos séculos XVI-XVII, que pode ser considerada um dos principais fatores desencadeantes do pensamento da Modernidade. A "nova Ciência" que neste momento se constitui pode ser ilustrada pelo 
modelo heliocêntrico de sistema solar formulado por Nicolau Copérnico [...], e que se opõe ao modelo geocêntrico de cosmo da tradição aristotélica, formulado na Antiguidade Clássica por Cláudio Ptolomeu [...]. (MARCONDES, 2010, p. 20)

Essa mudança de concepção e o surgimento de uma nova ciência repercutiu nas concepções de mundo, homem, sociedade, natureza, em todos os fundamentos de ciência, pois "equivale a uma crise não apenas científica, [...] mas sobretudo uma crise metodológica, que afeta uma concepção tradicional de método científico, bem como uma crise de visão de mundo, de concepção da natureza e do lugar do homem [...]" (MARCONDES, 2010, p. 20-21). Tensões essas que atingiram diferentes áreas do conhecimento despertando a falta de credibilidade no modelo em conflito. Diante de sua total insuficiência para resolução de situações problema e até mesmo das crises, o paradigma é visto como um modelo defasado, sem utilidade no cenário que se apresenta com novas situações emergenciais. Surgindo a partir daí um dos maiores desafios da Modernidade:

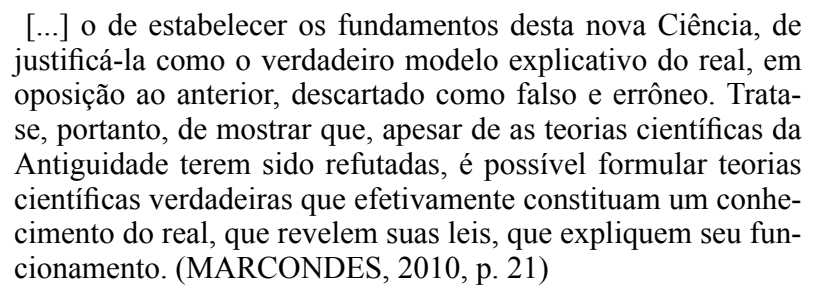

$\mathrm{Na}$ modernidade, via-se no meio das comunidades científicas a responsabilidade de resgatar a confiança evitando que novas teorias viessem a ser também descartadas. Diante de transições tão drásticas, pairou-se uma total insegurança quanto à construção de novas bases teóricas que pudessem conduzir o novo contexto. A comunidade vivenciou momentos de incerteza, sentimentos órfãos foram explicitados no decorrer dessa desestruturação nas suas bases teóricas. Sobre este cenário também Santos (2006, p. 17) afirma que "[...] perdemos a confiança epistemológica; instalou-se em nós uma sensação de perda irreparável tanto mais estranha quanto não sabemos ao certo o que estamos em vias de perder [...]”. Assim, mediante estas incertezas, busca-se a evolução das ciências, novos paradigmas que direcionem uma sociedade e resgatem a estabilidade perdida. Nesse sentido, Plastino afirma que:

Segundo a concepção Kuhniana, a evolução das Ciências se caracteriza por uma especialização, pela separação crescente das disciplinas científicas e por uma conduta do científico que o leva a despreocupar-se das questões gerais vinculadas à signi- 
ficação global de suas pesquisas, limitando-se aos problemas específicos de sua disciplina. (2010, p. 34)

A valorização crescente da produção do conhecimento por disciplinarização, isto é, por áreas, que acredita que a realidade complexa que apresenta o problema no contexto de um todo pode ser compreendida através das partes, da fragmentação, coloca em questionamento esta dualidade: "[...] a especialização das disciplinas e sua autonomia frente ao contexto global de sua produção, isto é, as problemáticas social, econômica, política e cultural das sociedades nas quais esta produção se realiza" (PLASTINO, 2010, p. 35). Indaga-se, então, sobre a complexa realidade do ser humano estar dissociada do campo que estuda, do que compreende a sociedade e tudo que a envolve.

Dessa forma, no percurso da linearidade "as leis da ciência moderna são um tipo de causa formal que privilegia o como funciona das coisas em detrimento de qual o agente ou qual o fim das coisas. É por esta via que o conhecimento científico rompe com o conhecimento do senso comum" (SANTOS, 2006, p. 30); Segundo Santos, um pensamento que busca a ordem e a estabilidade sem querer viver o risco das contradições, das incertezas e delimita o seu campo com " $[. .$.$] um conhecimento mínimo que fecha as portas a muitos outros sa-$ beres sobre o mundo, o conhecimento científico moderno é um conhecimento desencantado e triste que transforma a natureza num autómato [...]" (2006, p. 53). Além de perceber que "essa visão descontextualizada e simplificadora, difundida pela ciência moderna, tornou-se hegemônica ao longo dos últimos 400 anos e manteve latente a questão da complementaridade dos pares binários" (SANTOS, 2009, p. 18). Essa visão de caráter extremamente positivista começa nas últimas décadas a entrar em conflito. No âmbito educacional, com sua crescente fragmentação, esse início de crise surge a partir da percepção de que a dualidade limita muito o contexto do ser humano. Nesse cenário,

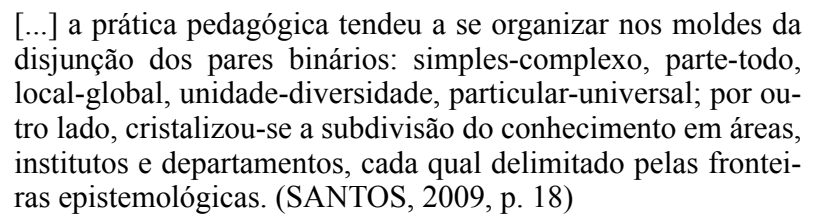

Diante dessas limitações, viu-se a impossibilidade de avanços dentro deste modelo dicotômico, percebendo-se, assim, a importância de desenvolver uma prática pedagógica contextualizada e global, partindo do contexto social dos sujeitos envolvidos no processo educativo, compreendendo que "essa fragmentação proposta pelo pensamento científico moderno vem deixando marcas 
profundas no ser humano. Uma delas é a crença de que a teoria sobrepõe-se à realidade [...]. E sabemos que as coisas não são bem assim" (MORAES, 2008, p. 266). Portanto, foi se tornando impossível continuar a desenvolver um trabalho educativo pautado na fragmentação e na linearidade do saber em que a contextualização não se fazia presente. Diante das novas situações que se apresentavam, surgiram indagações para as quais o paradigma da ciência moderna não tinha respostas.

\begin{abstract}
Sendo um conhecimento disciplinado, isto é, segrega uma organização do saber orientada para policiar as fronteiras entre as disciplinas e reprimir os que as quiserem transpor. É hoje reconhecido que a excessiva parcelização e disciplinarização do saber científico faz do cientista um ignorante especializado [...]. (SANTOS, 2006, p. 74)
\end{abstract}

A partir dessa compreensão referente às limitações do conhecimento disciplinar, Moraes (2008, p. 267) também afirma que "essa fragmentação proposta pelo pensamento científico moderno vem deixando marcas profundas no ser humano. Uma delas é a crença de que a teoria sobrepõe-se à realidade e, muitas vezes, tomamos a definição como se ela fosse a própria coisa definida".

Em contrapartida a este modelo disciplinar, surge um novo paradigma, que busca tanto compreender o problema quanto resolvê-lo em sua totalidade complexa, valorizando o saber que tinha sido considerado vulgar e descartado. Nesse contexto de transição paradigmática, Santos (2009, p. 36) afirma que "as teorias podem se transformar em paradigmas que norteiam as ações humanas num dado momento histórico, porém se defasam quando seus instrumentos conceituais não mais explicam os fenômenos que emergem do desenrolar da vida no planeta". Diante desta percepção, em crise, começa-se a transição do paradigma tradicional para um novo paradigma. Neste período percebe-se que:

[...] a crise do paradigma da ciência moderna não constitui um pântano cinzento de cepticismo ou de irracionalismo. É antes um retrato de uma família intelectual numerosa e instável, mas também criativa e fascinante, no momento de se despedir, com alguma dor, dos lugares conceituais, teóricos e epistemológicos, ancestrais e íntimos, mas não mais convincentes e securizantes, uma despedida em busca de uma vida melhor a caminho doutras paragens onde o optimismo seja mais fundado e a racionalidade mais plural e onde finalmente o conhecimento volte a ser uma aventura encantada. A caracterização da crise do paradigma dominante traz consigo o perfil do paradigma emergente. (SANTOS, 2006, p. 58) 
Assim sendo, o paradigma da modernidade já não conseguia atender as necessidades emergentes. A realidade que se apresentava já se diferenciava completamente das previsões, a cada dia o inesperado emergia e a partir desse quadro necessariamente principiaram a surgir novos caminhos, uma nova ciência que começa a perceber saberes diferentes e, ainda, que há a possibilidade de se dialogar, entendendo que nem tudo é descartado ou considerado impróprio. Ao contrário, de acordo com Moraes compreende-se esse paradigma

\begin{abstract}
[...] com base em um enfoque relacional, em que conceitos e teorias soberanos convivem com teorias rivais, [...] como também reconhece que as mudanças paradigmáticas convivem, simultaneamente, com outras experiências, teorias, outros conceitos ou fenômenos recalcitrantes que não se ajustam facilmente ao paradigma vigente. [...] oferece uma ideia mais completa da evolução do conhecimento científico, que, além de crescer em extensão, também se modifica, transforma-se mediante rupturas que ocorrem na passagem de uma teoria à outra (MORAES, 1997, p. 32).
\end{abstract}

A autora apresenta um contexto em que a transição paradigmática ocorre com mudanças de conceitos, teorias e ideias, mas também com a existência dos diálogos, compreendendo que o ser humano é completo e que a produção do conhecimento necessita estar interligado com diferentes saberes. Dessa forma, percebe-se o caminho transdisciplinar "que se apresenta não apenas como um princípio teórico-epistemológico do processo de construção do conhecimento, mas que está presente nas ações cotidianas, na convivência social, na convivência com a natureza e do aprendiz consigo mesmo" (MORAES, 2008, p. 265). Esta ótica busca a interlocução não nas partes, mas sim no todo que abrange a vida, o planeta num contexto contemporâneo, já considerado como pós-moderno. Nesse viés, também Boaventura Sousa Santos afirma que:

A ciência pós-moderna procura reabilitar o senso comum por reconhecer nesta forma de conhecimento algumas virtualidades para enriquecer a nossa relação com o mundo. É certo que o conhecimento do senso comum tende a ser um conhecimento mistificado e mistificador mas, apesar disso e apesar de ser conservador, tem uma dimensão utópica e libertadora que pode ser ampliada através do diálogo com o conhecimento científico. (2006, p. 88-89)

A partir dessa nova forma de ver o mundo e compreender a importância das interlocuções, a produção do conhecimento na ótica da criatividade adentra a perspectiva do paradigma emergente. As suas bases epistemológicas fundamentam-se na visão transdisciplinar e transformadora valorizando as práticas 
pedagógicas que estejam voltadas para o todo que envolve a vida. Esta nova forma de produção faz-se presente em um contexto educacional diferenciado que emerge na contemporaneidade, numa sociedade que vivencia a realidade cheia de controvérsias e adversidades sociais, humanas e ambientais. No entanto, a criatividade, busca fazer dos infortúnios, novas oportunidades de crescimento e superações, pois valoriza a contínua construção e interlocução dos novos saberes.

\section{Criatividade nas práticas pedagógicas transdisciplinares}

Na perspectiva de valorizar o contexto social, humano e planetário abrangendo a completude da vida de forma que tudo esteja interligado é que "o conhecimento do paradigma emergente tende "[...] a ser um conhecimento não dualista, um conhecimento que se funda na superação das distinções tão familiares e óbvias que até há pouco considerávamos insubstituíveis [...]" (SANTOS, 2006, p. 64). Nesta concepção de conhecimento integrador, onde o todo faz parte do ser humano e, ainda, é imprescindível para a produção do conhecimento é que se considera que, no campo educacional, "[...] o uso da imaginação e da criatividade são os melhores aliados do conhecimento" (SUANNO, 2013, p. 41). A partir desta visão criativa, "busca-se, então, construir práticas pedagógicas transdisciplinares que ajudem o aluno desenvolver articuladamente razão, emoção, percepção e consciência a fim de construir conhecimento e de construir uma nova arte de viver" (SUANNO; SILVA, 2013, p. 46).

De acordo com Maura (2009, p. 74) compreender “[...] a criatividade a partir de um olhar transdisciplinar" é ter uma percepção diferenciada para com a educação no sentido de integrar as oportunidades e conhecimentos para favorecer a formação e transformação humana, pois,

\footnotetext{
O olhar transdisciplinar nos abre caminhos até uma atitude integradora de saberes que não se circunscrevem ao conhecimento demonstrativo disciplinar, mas ao conhecimento aberto a outras aprendizagens que estão entre, através de e além do próprio conceito disciplinar e, sobretudo, dá a oportunidade [...] para uma atitude aberta e criativa, para a leitura e interpretação do que há em seu ambiente, através de óticas diferentes e pouco usuais, mas que são necessárias para conseguir uma formação completa (MAURA, 2009, p. 74).
}

Nesse sentido, há uma visão diferenciada em relação ao período da modernidade que valorizava, no campo do saber, apenas o conhecimento científico como um saber único que conseguiria atender a humanidade. Pois a pós- 
modernidade percebe que ainda há a necessidade de se refletir sobre ações que propiciem avanços, visto que "os males desta parcelização do conhecimento e do reducionismo arbitrário que transporta consigo são hoje reconhecidos, mas as medidas propostas para os corrigir acabam em geral por os reproduzir sob outra forma" (SANTOS, 2006, p. 75). Ou seja, ainda em retrocesso, continuam buscando nas novas disciplinarizações, a possibilidade de resolver as recentes problemáticas, querem trazer para as dificuldades contemporâneas as soluções da modernidade.

Diferentemente, na perspectiva da criatividade, com uma visão transdisciplinar, a educação começa a reconhecer que existe no ser humano a capacidade de gerar, de criar, de superar o que já existe, e de ser criativo no enfrentamento de situações conflituosas a partir do agregar-se aos novos conhecimentos. Este novo caminho parte de um contexto educacional com práticas pedagógicas criativas no olhar do paradigma emergente que se opõe a um ensino fragmentado, compreendendo que:

\begin{abstract}
[a] criatividade não pode ser considerada uma sucessão de coisas que partem do nada, porque o ser humano só é capaz de criar a partir daquilo que conhece, até mesmo precisa interiorizar as aprendizagens a partir das relações estabelecidas com o mundo. A partir delas é possível rearranjar as ideias, descobrir, criar[...] (THORNE, 2008, apud, CARNEIRO, 2013, p. 137)
\end{abstract}

Portanto, importar-se com um ambiente motivador que desperta no ser humano o querer criar, pode propiciar o saber além do previamente planejado, pois a ideia criativa vem a partir de conhecimentos adquiridos anteriormente, e está no constante aprender à medida que interage com o outro, com a vida, com o mundo, tornando-se motivador no despertar de novas descobertas. Assim a criatividade "[...] manifesta-se em ideias, ações, realizações, mas é um potencial vibracional subjacente em todo ser com capacidade transformadora" (MAURA, 2009, p. 76). Além de ser percebida como algo original e novo, é sobretudo formadora e integradora porque "consiste, entre outras coisas, em uma visão singular do mundo que se faz acompanhar da emoção e isso ajuda o ser humano a refletir sobre a realidade. Portanto, é somente a partir das experiências e dos conhecimentos anteriores que é possível criar" (CARNEIRO, 2013, p. 137).

Diante da concepção de Carneiro (2013) acerca de como surge a criatividade, destaca-se também a importância de valorizar os saberes que cercam o ambiente de vivências cotidianas do educando para além dos muros educativos. Compreender, nessa construção do criar, a importância da contextualização no desenvolvimento do fazer pedagógico criativo e prazeroso, de 
"um pensamento informado, estimulado e ordenado é de uma riqueza extraordinária para a aprendizagem [...]" (MAURA, 2009, p. 79), mesmo que em determinados momentos, nos contextos educacionais, situações conflituosas sejam vivenciadas.

Os conflitos, vistos de maneira desafiadora, contribuem para a constante produção de novos conhecimentos. Assim, é indispensável que o educador não seja somente um agente que colabora com a formação e transformação, mas que ele compreenda que o seu "papel de incentivador e motivador ocupa um lugar preeminente no tocante à criatividade" (TORRE, 2008, p. 82). Neste cenário, é imprescindível que tudo favoreça para que a criatividade floresça prazerosamente em toda ação educativa, pois

[...] o ambiente relaxado, os estímulos positivos, a paz e o que agora chamamos inteligência emocional têm um papel importante no processo criativo já que garantem um estado afetivo positivo que não é senão a consciência e a gestão das próprias emoções para uma gestão satisfatória e positiva da criatividade. (MAURA, 2009, p. 77)

Com base na visão desta autora, entende-se que para ser criativo é importante estar aberto ao novo, também que venha partir do próprio indivíduo este interesse de ir além do vivenciado e deixar florescer em seu interior o desejo de criar, seja diante dos anseios de novas perspectivas em seu cotidiano ou até mesmo mediante a situações adversas. A partir desta pretensão, todo o esforço e dedicação junto ao ambiente estimulador propiciará ações criativas.

Além do querer humano, o processo criativo pode surgir em ambientes desestabilizadores, uma vez que as dificuldades são acontecimentos normais que fazem parte da vida humana e, portanto, precisam ser vistas no processo educativo como adversidades criadoras de oportunidades que favorecem o crescimento. Isto porque entende-se

[...] que a partir da capacidade de pensar a adversidade como adversidade criadora, seja possível redimensionar o ensino, por permitir ao docente e ao discente que tomem consciência do potencial criativo subjacente em situações adversas, e assim, construam sua própria capacidade de promover mudanças e enfrentar a realidade que se apresenta adversa, porém que pode ser modificada, transformada, por meio de ações criativas, humanas e éticas para o enfrentamento das adversidades da humanidade (SUANNO; SILVA, 2013, p. 54-55).

Nesse sentido, percebe-se que o ser humano possui uma capacidade criadora que pode ser desenvolvida de acordo com o enfrentamento das adver- 
sidades e da percepção de transformação da realidade apresentada como adversa. Pois, o religar, agregar e contextualizar no processo educativo propicia "[...] o aprendizado de forma mais integral, que interliga o sentir, o pensar e o agir, que estimula a criatividade, a interação e a ação do aluno em seu processo de aprendizagem" (MORAES, 2008, p. 265). Assim, o educador no cenário educativo, dentro deste paradigma emergente, em que a produção transdisciplinar considera, além do que está explicito, todos os conhecimentos da vida como saberes essenciais para o ser humano num contexto completo da realidade, percebe que

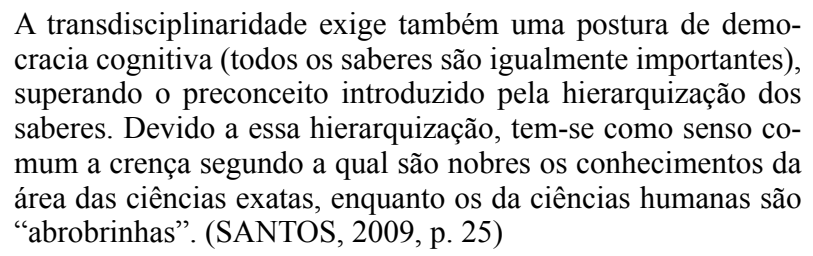

Esta nova perspectiva no processo educacional reconhece as diversas áreas da ciência como conhecimentos indispensáveis e com o mesmo nível de importância, nenhuma pode sobrepor a outra, mas devem dialogar e agregaremse para a complementação do aprender e apreender-se onde "a incerteza e a ambiguidade, apesar de fontes de desconforto, são territórios da criatividade" (SOMMERMAN, et al. 2009, p. 119). Nesta ótica, além do conhecer também há a preocupação com o ser, com a importância de valorizar o educando como ser protagonista do seu próprio aprender, de um espaço humanizador que:

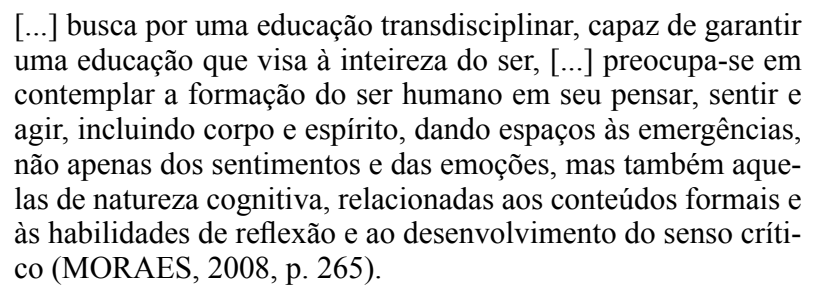

Assim é uma educação criativa que contempla uma visão global contextualizada, atendendo os aspectos humanos, sociais e ambientais. Transformando o espaço educativo para além dos muros territoriais e fazendo com que o seu mundo faça parte do aprender e vice e versa. Este novo olhar requer uma prática pedagógica que esteja atenta ao todo, de maneira consciente, integrando saberes por meio de projetos e ações que complementam o cotidiano pedagógico destacando atitudes que sobressaem ao proposto. Para tanto, desenvolve ações 
pedagógicas que estimulam "os atributos mais característicos da criatividade, tais como a originalidade, flexibilidade, elaboração, inventividade" (TORRE, 2008 , p. 83), favorecendo a integração do ser, do aprender e o viver no contexto repleto de oportunidades produtivas do conhecimento.

Nesta prática, a criatividade é uma constante aliada no âmbito educacional; a concepção de ver o indivíduo em sua inteireza de ser e viver propicia práticas pedagógicas criativas, nas quais “[...] um processo ativo, parte de uma ideia para transformá-la, mudá-la, aumentá-la, combiná-la para conseguir resultados imaginativos e criativos que são intencionais e contextualizados" (MAURA, 2009, p. 77). Esta criatividade que visa a formação e transformação do ser, da vida, faz parte de um novo paradigma, o paradigma emergente que está na contemporaneidade com uma visão do todo, global, que reconhece a importância do conhecimento científico e de todos os outros saberes também como essenciais para vida.

\section{Considerações finais}

A produção do conhecimento na ótica de Thomas Kuhn e Boaventura Sousa Santos é compreendida desde o período da modernidade apresentando uma trajetória de muitos conflitos, crises e revoluções que contribuíram para o fortalecimento de conceitos tanto da ciência moderna, quanto na transição para um novo paradigma.

No novo paradigma emergente está a criatividade atuando no âmbito educacional com uma concepção diferenciada de um período em que a cientificidade era considerada como única forma de produção de conhecimentos. A sua perspectiva, criativa, caminha em direção ao objetivo de valorizar o bem comum que abrange tanto o individual, quanto o social e o ambiental. Ou seja, considera a vida que se faz presente no planeta, importante para a sobrevivência humana em todas as suas dimensões. Nesse sentido, vê, na transdisciplinaridade, a valorização dos diferentes saberes, a perspectiva inovadora e transformadora para o contexto educacional.

Este caminho da criatividade anda na contramão do paradigma tradicional que foi marcado pelo período da ciência moderna, da divisão do conhecimento, dos saberes fragmentados pela disciplinarização e, sobretudo, pela importância exclusiva ao conhecimento produzido pela ciência, legitimado por uma comunidade científica que pertencia ao paradigma hegemônico. Assim, com esta visão criativa, diferenciada deste período conservador, busca-se integrar o ser humano com a natureza, trabalhando o respeito, o amor, a vida, a ética e a solidariedade. 
Nessa ótica, percebe-se que é imprescindível que as práticas pedagógicas estejam pautadas na concepção de criatividade que valoriza o todo, a vida, que incentiva o criar, o descobrir, o diálogo, a expressão livre, o pensar, o sentir, e sobretudo, a constante busca de superação das adversidades que fazem parte da vida. Uma acepção que visualiza além de seu espaço próprio, individual, que vai além dos muros educacionais, mas que religa e transcende os padrões modernos de se produzir conhecimento.

\section{Referências}

CARNEIRO, Maria Angela Barbato. Criatividade: potencial a ser desenvolvido em profissionais da Educação Infantil. In: SUANNO, Marilza Vanessa Rosa; DITTRICH, Maria Glória \& MAURA, Maria Antonia Pujol. (Orgs.) Resiliência, Criatividade e Inovação: potencialidades transdisciplinares na educação. Goiânia: UEG/Ed. América, 2013. p. 131-146.

KUHN, Tomas Samuel. A estrutura das revoluções cientificas. São Paulo: Perspectiva, 1970. (Col. Debates.) 257 p.

MARCONDES, Danilo. A crise de paradigmas e o surgimento da modernidade. In: BRANDÃO, Zaia. (Org.) A crise dos paradigmas e a educação. 11. ed. - São Paulo: Cortez, 2010. p. 17-31.

MAURA, Maria Antonia Pujol. Educação Infantil como estado permanente da criatividade. In: ZWIEREWICZ, Marlene; TORRE, Saturnino de lá. Uma escola para o século XXI: Escolas criativas e resiliência na educação. Florianópolis: Insular, 2009. p. 71-85.

MORAES, Maria. Cândida. O paradigma educacional emergente. Campinas - SP: Papirus, 1997. $239 \mathrm{p}$.

Ecologia dos saberes: complexidade, transdisciplinaridade e educação: novos fundamentos para iluminar novas práticas educacionais. São Paulo: Antakarana/ WHH - Willis Harman House, 2008. 303 p.

PLASTINO, Carlos Alberto. A crise dos paradigmas e a crise do conceito de paradigma. In: BRANDÃO, Zaia. (Org.) A crise dos paradigmas e a educação. 11. ed. - São Paulo: Cortez, 2010. p. 33-49.

SANTOS, Akiko. Complexidade e transdisciplinaridade em educação: cinco princípios para resgatar o elo perdido. In: SANTOS, Akiko; SOMMERMAN, Américo. (Orgs.) Complexidade e transdisciplinaridade: em busca da totalidade perdida. Conceitos e práticas na educação. Porto Alegre: Sulina, 2009. p. 15-38.

SANTOS, Boaventura Sousa. Um discurso sobre as ciências. 4 ed. São Paulo: Cortez, 2006. $92 \mathrm{p}$.

SOMMERMAN, Américo; et al. O que há entre teoria e prática? Há o mundo da vida. In: SANTOS, Akiko; SOMMERMAN, Américo. (Orgs.) Complexidade e transdisciplinaridade: em busca da totalidade perdida. Conceitos e práticas na educação. Porto Alegre: Sulina, 2009. p. $99-126$. 
SUANNO, João Henrique. Adversidade, resiliência e criatividade: uma articulação oportuna? In: SUANNO, Marilza Vanessa. Rosa; DITTRICH, Maria Glória \& MAURA, Maria Antonia Pujol (Orgs.) Resiliência, criatividade e inovação: potencialidades transdisciplinares na educação. Goiânia: UEG/Ed. América, 2013. p. 31-42

SUANNO, Marilza Vanessa Rosa; SILVA, Carlos Cardoso. Resiliência, adversidade criadora e educação. In: SUANNO, Marilza Vanessa Rosa; DITTRICH, Maria Glória \& MAURA, Maria Antonia Pujol (Orgs.) Resiliência, criatividade e inovação: potencialidades transdisciplinares na educação. Goiânia: UEG/Ed. América, 2013. p. 43-57

TORRE, Saturnino de la. Criatividade aplicada: recursos para uma formação criativa. Trad. WIT Languagens. São Paulo: Madras, 2008. p. 81-103.

Submissão em: 27/11/2014

Aceite em: 14/03/2015

Maria José de Pinho é professora do programa de pós-graduação em Ensino de Língua e Literatura, e Mestrado em Educação da Universidade Federal do Tocantins. Coordenadora local do grupo de pesquisa em Rede Internacional Investigando Escolas Criativas e Inovadoras. Mestre em Educação pela Universidade Federal de Pernambuco (1994) e Doutor em Educação pela Pontifícia Universidade Católica de São Paulo (2004). Endereço para correspondência: Reitoria da UFT - 109 Norte, Av. NS-15, ALCNO 14, S/N, Bloco 4, Sala 207. CEP 77.001.090, Palmas - TO. E-mail: mjpgon@uft.edu.br

Kênia Paulino de Queiroz Souza é mestranda em Educação pela Universidade Federal do Tocantins - UFT. Graduada em Pedagogia pela Faculdade de Ciências e Letras de Paraíso - FECIPAR (2004). Especializações em Supervisão e Orientação Educacional pela Faculdade JK - Brasília (2007), e em Educação Infantil e Séries Iniciais pela Faculdade João Calvino (2013). Membro do Grupo de Pesquisa em Rede Internacional Investigando Escolas Criativas e Inovadoras. E-mail: keniaqueiroz06@hotmail.com 